are ejected in laterally limited streams, the direction of which varies as the sun rotates. When such a stream happens to impinge on the earth, the air becomes highly ionised in the atmospheric regions affected, which are situated geographically within about $20^{\circ}$ of the poles of the axis of magnetisation of the earth, though they spread farther towards the equator when the streams are specially intense. The corpuscles can penetrate the earth's atmosphere down to not less than $80 \mathrm{~km}$. above the ground; they impinge not only on the side of the earth facing the sun, but also bend round to the right side of the earth, where they produce visible auroræ. The deflexion of the corpuscles towards the magnetic poles is due to the earth's magnetic field, and indicates that the streams have a slight excess charge and are ionised.

The ionisation of the auroral zones renders these regions of the atmosphere highly conducting, and permits intense electric currents to flow in them; the changing magnetic field of these currents is observed as a magnetic storm (or lesser disturbance). Even if auroræ were not visible, the magnetic observations would indicate the existence of highly conducting upper air in polar regions.

The ionisation of the air due to the solar corpuscles is much less uniformly distributed than the ionisation over the sunlit hemisphere due to ultra-violet radiation; the limited distribution of bright auroræ gives visible indication of this. Also the ionisation by corpuscles varies irregularly with time, and cannot be predicted at present with any certainty ; it depends both on the activity and presentation (towards the earth) of the disturbed solar areas. If such an area remains active after the lapse of a solar rotation period (about 27 days), it may affect the earth a second time, or even several times after successive rotations. Hence arises the clearly marked tendency for magnetic disturbance to recur after 27 days; but this is only a tendency, for the direction of the stream from a solar disturbed area may change, or the area may not remain long active.

The influence upon wireless transmission of the regular change of ionisation from day to night has long been recognised; the improved conditions at night, especially for long waves, are naturally accounted for by the withdrawal of the refracting ionised layer to greater heights at night, where the ions have longer free paths and where their less frequent collisions dissipate less of the energy acquired from the electric waves. The influence upon wireless of the less regularly distributed but occasionally very intense ionisation due to solar corpuscles has only Jately become reasonably certain. The effects are likely to be complicated, and it will doubtless be a long time before they are clearly ascertained. An interesting feature suggested by recent observations is that transmission from Europe to America is more affected than that from Europe to the East. This is not unexpected, in view of the inclination of the earth's magnetic to its geographical axis; the centre of the north auroral zone is about $10^{\circ}$ from the geographical north pole, in the direction of Canada, and auroræ are observed in Canada in much lower latitudes than in Europe. The region of abnormal corpuscular ionisation will therefore extend about $20^{\circ}$ farther towards the equator in Canada than in Russia.

\title{
The Decimal Classification of Melvil Dewey and its Extension by the Brussels Institute of Bibliography.
}

By Dr. S. C. Bradford, The Science Library, S.W.7.

$\mathrm{T}^{\mathrm{H}}$ HE study of classification is a necessary preliminary to the preparation of a comprehensive guide to recorded information. Of the multifarious systems that have been suggested for the classification of literature, Dewey's "Decimal Classification and Relative Index," first developed in 1873 , seemed the most hopeful of any produced hitherto, and was hailed with jubilation in many quarters. But, although it proved successful for the purpose for which, in the first place, it was designed, i.e. the classification of books, it has been found inadequate when applied to greater bibliographical detail, such as individual scientific and technica] papers. In its original form it is therefore unsuitable for the preparation of a detailed index to the records of human work and thought.

Dewey's scheme comprises two parts : a classification in which more or less logically arranged subdivisions of knowledge are given separate arbitrary numbers, and an alphabetical index of subjects, regarded by Dewey as the more important feature of the system, to indicate the respective numbers of the subdivisions. The index aims at giving similar or synonymous words and the same words in different connexions, so that any person of intelligence can scarcely fail to get the right number. In this scheme the whole of knowledge is represented by unity, and divided into ten main divisions. The first, comprising all numbers between 0.0 and 0.1 , is assigned to works dealing with general subjects such as encyclopædias, bibliographies, etc., and those that cannot be allocated to the nine more definite subdivisions that follow. These are :
$0 \cdot 1$ Philosophy.
0.2 Religion.
0.6 Applied Science.
0.7 Fine Arts.

0.3 Social Sciences, Law. 0.8 Literature.

0.4 Philology, Languages, 0.9 History, Geography, 0.5 Pure Science. Biography.

Each of these main groups is again subdivided by addition of another decimal place, and further subdivision of these secondary and succeeding groups is obtained as desired. Thus :

0.5 Pure Science. 0.5315 Gravity, Ballistics. 0.53 Physics. 0.531 Mechanics. the Energy of Projectiles.

In practice the initial decimal point is omitted, and 
others may be intercalated to assist the memory or aid the eye. Thus catalogue titles, or abstracts, of books, pamphlets, monographs, papers, notes, etc., dealing with internal ballistics, are to be mounted on cards of uniform size and filed under the number 531.57; and no matter by what bibliographical agency the information is indexed, all the index cards relating to this subject fall together automatically. The student who requires to know what has been recorded on this subject, having ascertained the number from the alphabetical index to the subject-classification, can, by looking at the cards bearing this number, gain access immediately to all the information desired that has been rendered available.

The advantages of this system are: (1) Its simplicity: the order of filing is merely that of the decimal numbers, so that sorting of cards is mechanical ; (2) each subject is represented by a single decimal number occupying a definite position in numerical sequence and independent of the language in which the conception is expressed; (3) nine further subdivisions can be obtained as desired by addition of one more figure, and these new subdivisions can be inserted between two previously established divisions without disturbing their numerical order; and (4) the number representing a given conception can be ascertained from the alphabetical index without consulting the classification.

Dewey's classification contains also the germ of an idea which, developed afterwards by the Brussels Institute, converted his classification into a powerful instrument of bibliography. There are certain general groups into which bibliographical material may be divided that are independent of subject, or common to a large number of conceptions. Thus, at the head of each of the main subdivisions (e.g. of 5, Pure Science), there is a section

01 Philosophy, Theories.

02 Compends, Text-books.

03 Dictionaries, Encyclopædias.

04 Essays, Lectures, Addresses.

05 Periodicals.

06 Societies, Transactions.

07 Education, Methods of Teaching.

08 Collected Works.

09 History.

Such subdivisions relate to the form or purpose of the work. For example, the Proceedings of the Physical Society would be numbered 53.06. Again under geology, 55 , there is a section, 554 to 559 , to be subdivided by countries like geography, 94 to 99 . Altogether, a good many examples occur of the application of such an idea, but the classification, as published, was suitable for the purpose of arranging the books in the New York State Library, and the principle of common subdivisions was not developed in detail. If a universal guide to knowledge should be organised on the basis of the Decimal Classification, mankind will owe much to Melvil Dewey, and it is not the less to his credit that the original scheme proves inadequate when applied, as Dewey hoped, to the indexing of scientific papers as a whole.

However, the classification of separate articles requires much more subdivision than the grouping of works even on the largest scale. The main subject-classification itself requires to be more detailed, and when this has been developed as much as possible, there remain the various common aspects of a given subject to be dealt with. As an example, the number $661 \cdot 25$, in the extended classification, represents the sulphuric acid industry; and this requires to be further subdivided according to the process of manufacture. When this has been done, we have yet to provide for a variety of considerations that may apply to the number 661.25 or to its subdivisions. For example, there will be papers on theoretical or experimental studies relating to the manufacturing process, at the start, while in use, or after modification; papers from the point of view of realisation of the manufacture, such as gathering materials, special operations, raw materials, accessory products, machines employed, fixed machinery, engines, machine tools, implements, results obtained, by-products, fittings and apparatus; papers from the economic point of view, such as cost of materials, labour, selling price ; and from the point of view of premises, sites, and personnel of various kinds.

These and other general points of view are common to the various branches of the sulphuric acid industry, as well as to a vast number of specific subject-divisions. Again, it will be necessary, in many cases, to classify bibliographical material according to place, time, or language, or, it may be, according to the form of the work. Thus, sulphuric acid manufacture may need to be treated from the point of view of country, or period, or it may be desired to distinguish between large treatises, manuals, books of tables, popular descriptions, collected papers or historical studies.

Now although, as it has been stated, Dewey's classification contains the germ of an extension by common subdivisions, this was not developed, and his tables have no places for grouping material by common headings such as have been mentioned. Indeed, to provide for such subdivision as necessary in each case, without perfecting a system of general classes, would have increased the size of the classification to several hundred volumes. For this reason his scheme in its original form is hopelessly unsuitable for the preparation of a comprehensive index to knowledge, and appears never to have been used for bibliographical work on a large scale.

This was the state of affairs when, in 1895, the first International Conference on Bibliography was held in Brussels. The Conference had to search in a spirit of impartiality for the principles on which could be established a universal bibliographical classification. It decided that the Dewey system was based on such principles and was capable of being transformed into a highly satisfactory classification. As a result of the Conference, the Institut International de Bibliographie was founded, which undertook the work of perfecting the Dewey code.

The classification itself was considerably extended, and, in addition, the conception of auxiliary tables for common subdivisions was developed. These are of two kinds : (1) Analytical subdivisions

No. 2994, VoL. 119] 
that relate to special subjects only, and (2) common subdivisions that may be added to any item of the classification. For example, general operations in photography are made into a group of special analytical subdivisions that are available for arranging matter relating to any of the various photographic processes. The numbers representing such subdivisions are preceded by a zero. For example, toning is one such division, represented by 0235 , and this number can be added to any of the numbers representing a photographic processthus 77.21 denotes silver processes in general, and $77 \cdot 21 \cdot 0235$ means toning in relation to processes based on the use of silver salts.

Besides these special subdivisions that relate to particular parts of the classification, there are five tables of common subdivisions that may be used in any connexion. The first relates to the form of the publication, and is developed from the general subdivisions of the Dewey scheme described above, the numbers being enclosed in parentheses. Thus (05) represents a periodical, so that a magazine restricted to acetylene welding, for example, can be indicated by adding (05) to the number for that process as $665 \cdot 882(05)$. Table II. comprises the geographical subdivisions. These are also enclosed in parentheses. Thus (493) denotes Belgium. Consequently sulphuric acid manufacture in Belgium would be $661 \cdot 25(493)$. Table III. has subdivisions by language and Table IV. by time. The fifth of these common groups includes all subdivisions corresponding to general points of view. These are indicated by numbers commencing with a double zero; e.g. 00311 represents net cost of the raw materials. If it is desired to classify a paper on that aspect of the sulphuric acid industry, it would be numbered $661 \cdot 25 \cdot 00311$; and these ten figures represent an idea requiring eleven words to express it in English.

By such a logical extension of Melvil Dewey's scheme it was converted into a beautiful bibliographical tool of the greatest power that is suitable for work of the finest detail; and in order that the classification may be kept up-to-date, a Commission was established to issue additions as needed. From time to time, with the progress of science and invention, new divisions become necessary and are published by the Commission. Or, an expert who discovers the need may suggest a considered extension of the scheme, and if this is drawn up in accordance with the principles of the classification, it will be incorporated.

\section{Obituary.}

Prof. E. H. Rennie.

TIME irresistibly takes its terrible toll and the 1 names left upon the roll of our old guard are now very few. The Australian mail just in brings me a copy of the Adelaide Register of Jan. 10, with an account of the sudden death of my old friend, Prof. Edward H. Rennie. He seemed to be in good health but on Saturday, Jan. 8, going into the garden, he took a drink of water, lay down-and just died. A few days previously, I had received a long chatty letter from him, dated Dec. 20. In this he speaks of having had a very strenuous year and feeling somewhat played out. During the first six months, he had been acting vice-chancellor of the University; then came the University jubilee and after this the meeting at Perth, of the Australasian Association for the Advancement of Science, of which he was president. Added to this, he had much anxiety on account of the illness of his wife and daughter. He tells me of the journey across the arid region to Perth, lasting three days. At one part, the railway runs in an undeviating straight line, nearly 400 miles, across flat desert, where nothing was growing, he says, over about 2 feet high, the horizon being unbroken by a single tree or elevation of any kind. People seldom realise how much of Australia is country of this order. "Aboriginals were seen here and there almost in their primitive condition, except that they wore clothes."

Rennie's first communication to the Chemical Society was made with Alder Wright. He then worked with me at the London Institution. The record of our work appeared only in the Chemical News. I was greatly attracted to him and was hoping to secure him as my chief assistant at the
Finsbury Technical College, at the opening in $\mathbf{1 8 8 3}$, but a more tempting offer came from home and he returned to Australia in 1882. Two years later, he became professor in Adelaide University. I visited him in 1914, reaching Adelaide a week ahead of the Association, in order to stay quietly with him. I then gained some idea of the man's devotion to his post and the great burden of work upon his shoulders. Rennie's services to his University as a teacher cannot be over-rated. $\mathrm{He}$ was extraordinarily thorough, deliberate and exact in his outlook and work, a most painstaking teacher. His scientific services to Australia are also to be ranked very high, though unfortunately, owing to the calls upon him as teacher and administrator, he had but little spare time for original inquiry. He devoted himself particularly to the study of native materials. Perhaps his most interesting discovery was that of trihydroxymethylnaphthaquinone in Drosera Whittakeri.

Australia is remarkable for its numerous species of long trailing Drosera. Rennie and $I$ spent a delightful day in the hills behind Adelaide and nothing interested me more, in my journey around the continent, than his digging up the Drosera tubers and showing me the beautiful glistening crystals of the hydroxyquinone present in the outer layers. Why or wherefore such a compound should so come to the surface in a plant is difficult to say.

We spent another day on the seashore tracking down Lotus australis, which I was anxious to compare with our corniculatus. We found it in quantity, highly cyanophoric, very like the dwarf plant growing at Ballantrae in the sandhills. I fancy corniculatus must have wandered to the Antipodes and changed its name.

No. 2994, VoL. 119] 